\title{
Educação Museal e Cibercultura: pensando conceitos, práticas de um campo em construção
}

\author{
Frieda Marti ${ }^{1}$ \\ Fernanda Santana Rabello de Castro ${ }^{2}$ \\ Andréa Fernandes Costa ${ }^{3}$
}

\section{APRESENTAÇÃO}

O intenso desenvolvimento das tecnologias digitais em rede vem transformando nossos modos de ser, estar e sentir o mundo. Os grandes avanços no campo das tecnologias da informação e da telecomunicação, como a digitalização, a internet, e posteriormente a world wide web abriram novas e diversas possibilidades de processamento, armazenamento, produção e circulação de informações e de conhecimentos, e podem ser considerados os primeiros catalisadores das intensas transformações sociotécnicas, culturais, políticas, econômicas e educacionais contemporâneas. As novas formas de comunicação emergentes no ciberespaço vêm, portanto, transformando as relações entre a técnica e a vida social, produzindo novas linguagens e signos, e desenvolvendo uma nova cultura contemporânea, a cibercultura. A cibercultura é a cultura contemporânea mediada e estruturada pelas tecnologias digitais em rede na relação cidade/ciberespaço.

A relação dos museus com as tecnologias digitais pode ser evidenciada a partir da década de 1960, mas é o cenário cibercultural que vem apresentando aos museus e a seus praticantes novos desafios frente às suas práticas comunicacionais e educacionais e ao patrimônio e a cultura.

\section{Submetido em: 31/08/2019 Aceito em: 31/08/2019 Publicado em: 31/08/2019}

${ }^{1}$ Graduada em Ciências Biológicas (Licenciatura/UERJ), Mestre Zoologia (Museu Nacional/UFRJ), Doutoranda da Faculdade de Educação (PROPED/UERJ). Integrante do Grupo de Pesquisa Docência e Cibercultura (GpDOc), coordenado pela Profa Dra Edmea Santos e do Grupo de Pesquisa Educação Museal: história, conceitos e políticas, do diretório do IBRAM no CNPq, coordenado pela Profa Dra Fernanda Castro.

${ }^{2}$ Graduada em História (UFRJ), Mestre em Educação (UFRJ), Doutora em Educação (UFF). Técnica em assuntos educacionais no MHN/Ibram. Professora Convidada do Mestrado Profissional em História da UNIRIO e coordenadora do Grupo de Pesquisa Educação Museal: história, conceitos e política do diretório do IBRAM no CNPq.

${ }^{3}$ Educadora museal na Seção de Assistência ao Ensino do Museu Nacional (UFRJ), Professora do Departamento de Estudos e Processos Museológicos e da Escola de Museologia (UNIRIO), Mestre e Doutoranda em Educação (PPGEdu/UNIRIO). Integrante do Grupo de Pesquisa Educação Museal: história, conceitos e políticas do diretório do IBRAM no CNPq, coordenado pela Profa Dra Fernanda Castro. 
No cenário nacional das políticas públicas voltadas aos museus e a sua função educativa, foi oficializada, por meio da Portaria 422 de 30 de novembro de 2017, a criação da Política Nacional de Educação Museal (PNEM), que define o conceito Educação Museal e dispõe sobre seus objetivos e práticas, princípios e diretrizes, e sobre os compromissos do IBRAM relacionados à sua promoção, desenvolvimento e implementação, dentre outros.

O presente dossiê reúne, portanto, um conjunto de produções acadêmicas e artísticas que discutem e apresentam de maneira heterogênea e plural a Educação Museal brasileira na contemporaneidade. Desde a sua apresentação visual, a edição número 3 da ReDoC nos remete ao universo da Educação Museal. Na capa, produzida por Manoel Magalhães, aludimos afetivamente ao Panapaná, objeto que era exibido em uma das salas do circuito expositivo do Museu Nacional e que era recordista de selfies e comentários na internet. A imagem nos remete à experiência lúdica, sensorial, emotiva que a educação museal oferece aos visitantes de museus.

$\mathrm{O}$ aspecto integral e multirreferencial da educação museal aparece em alguns dos textos que apresentamos nesse dossiê temático e que reúne reflexões e narrativas de diversos profissionais da área, alguns com trajetórias históricas no campo, outros com produções e realizações mais recentes. Contando experiências e criando conhecimento específico sobre o tema, esses educadores tratarão de temas que introduzem o leitor no universo da educação museal, abordando teorias e conceitos, realizando análises históricas, políticas e sociais sobre a prática educativa museal, seus desafios e conquistas.

Esse Dossiê Temático tem alguns objetivos principais: (1) apresentar ao campo da educação a realidade e os debates específicos do universo dos processos educativos realizados nos/pelos/para os museus; (2) destacar entre a produção de conhecimento em educação museal, que é dispersa, porém cada vez mais sistemática, os aspectos teóricos, metodológicos, práticos e políticos desse campo científico em construção; (3) reunir temáticas que demonstrem de forma abrangente e atual alguns dos principais debates presentes no campo e sua relação com a cibercultura.

Nesse sentido essa publicação apresenta dez artigos, duas resenhas de trabalhos acadêmicos, dois vídeos de ações educativas museais e uma exposição virtual que apresentam da teoria à prática, dos temas mais gerais aos mais específicos diferentes conteúdos e temas do universo dos museus em sua relação com a educação.

No artigo que abre o Dossiê intitulado Incursões sobre os termos e conceitos da educação museal, as educadoras e pesquisadoras Maria Esther Valente e Sibelle Cazelli, que possuem larga trajetória de atuação em museus e com a formação de educadores no Brasil, nos presenteiam, como elas mesmas dizem, com uma incursão pelos termos e conceitos que designam historicamente a ação educativa dos museus, trazendo à cena polêmicas em curso de um campo em construção. As autoras revisitam referências nacionais e internacionais que 


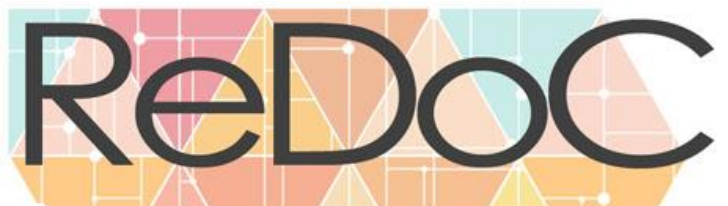

\section{Revista Docência e Cibercultura}

destacam controvérsias de linguagem e definição, motivadas por diferentes compreensões e usos de termos como educação formal, educação não formal, educação museal e seus usos práticos e teóricos. Referindo-se ao conceito de Bourdieu, apontam para o caráter histórico da educação museal que apresenta forte influência dos países de língua inglesa e francesa desenvolvendo-se como um campo científico em construção, com pouca autonomia e em processo de acúmulo de capital científico, mas cada vez mais apresentando características particulares no Brasil, como no caso do desenvolvimento da Política Nacional de Educação Museal (PNEM).

Seguindo a apresentação conceitual e terminológica do campo da educação museal, dessa vez em sua interface com a cibercultura, Frieda Marti, pesquisadora de doutorado do Programa de Pós Graduação em Educação da Uerj e colaboradora da Seção de Assistência ao Ensino do Museu Nacional, e Edméa Santos, Profa Titular da Faculdade de Educação da Universidade Federal Rural do Rio de Janeiro e Coordenadora do Grupo de Pesquisa Docência e Cibercultura introduzem, com o artigo Educação Museal Online: a Educação Museal na/com a Cibercultura, o cenário em que se inicia a relação entre os museus e as tecnologias digitais em rede, apresentando e explicitando termos e conceitos de campos entrelaçados: a educação, os museus e a cibercultura. As autora fazem um percurso histórico que vai desde o surgimento da internet, chegando às práticas contemporâneas de Educação Museal Online e, a partir de um referencial teórico que inclui Michel de Certeau e Nilda Alves, propõem um fazerpensar que nos leva a uma definição do que são esses processos educativos.

Em A formação inicial e continuada de educadores museais: projeto em construção, a educadora museal da SAE/MN e professora do curso de museologia da UNIRIO, Andrea Costa, traz à luz o necessário debate sobre a formação das educadoras e educadores museais, a partir de um breve panorama histórico, apresentando resultados de pesquisas nacionais e internacionais sobre o tema, mencionando os atuais debates colocados pela oficialização da Política Nacional de Educação Museal para questão da formação e sua relação com a profissionalização da educação museal. Demonstrando a importância dos museus e do espaço da prática para a formação dos profissionais de educação museal, Andrea traz à tona tensões e possibilidades de fortalecimento da educação museal como campo por meio do reconhecimento de seus profissionais no âmbito de sua formação inicial e continuada, apontando para o debate essencial sobre onde deve dar-se e com quais tipos de parcerias e interações.

Fernanda Castro, educadora do Museu Histórico Nacional/Ibram, aborda no artigo $A$ construção do campo da educação museal: políticas públicas e prática profissional o contexto de criação e desenvolvimento em caráter participativo da Política Nacional de Educação Museal para discorrer sobre uma ação fundamental colocada por essa política: a sistematização das ações educativas nos museus e a criação, no âmbito institucional, de Programas Educativos e Culturais (PECs) entendidos como políticas educacionais. São citadas referências nacionais e internacionais que apresentam sugestões e metodologias de elaboração de PECs e de planejamento de ações educativas museais, ao passo que é ressaltada a ligação entre a implementação da PNEM e o ato de sistematizar, planejar, registrar e avaliar essas ações. 
Carla Gruzman e Ozias Soares, educadores e pesquisadores do Museu da Vida, da FIOCRUZ, nos falam do cenário da pesquisa em educação museal, no artigo $O$ lugar da pesquisa na educação museal: desafios, panorama e perspectivas, perpassando a história da pesquisa em museus no Brasil, os autores demonstram a passagem do foco temático em acervos, coleções e processos museológicos ligados aos objetos e sua exposição para o foco no público e em sua relação com o museu e suas ações, a partir da década de 1980. Por meio de uma imersão na realidade cotidiana dos museus, apresentando sua estrutura, desenvolvimento histórico, político e a organização do trabalho educativo, Gruzman e Soares demonstram que a pesquisa em museus tem caráter particular, é parte também da formação dos educadores e, há tempos voltada para a prática, tem-se cada vez mais, num período recente, encaminhando-se para a abordagem de assuntos teóricos e metodológicos, contribuindo para o fortalecimento da educação museal como campo de produção de conhecimento a partir dos museus. Não deixam, porém, de salientar a importante dinâmica de criação de cursos de pós-graduação e grupos de pesquisa que tangenciam ou debruçam-se sobre a temática específica da educação museal. Indicando temáticas relevantes em estudos já realizados, os autores apresentam também os desafios e perspectivas para a pesquisa em educação museal no Brasil, demonstrando a importância e o potencial transformador que a investigação e a produção científica de conhecimento sobre o tema tem adquirido no cenário museal brasileiro.

Outro tema pungente e relevante, que move o campo museal e em especial o da educação museal nos últimos anos nos é trazido por Gabriela Aidar, educadora da Pinacoteca do Estado de São Paulo, em Acessibilidade em museus: ideias e práticas em construção. Mostrando exemplos de práticas de inclusão e acessibilidade na Pinacoteca de São Paulo, no Museo Nacional de Colombia e do Montreal Museum of Fine Arts, Aidar problematiza diferentes pontos de vista acerca da acessibilidade em museus e sobre as responsabilidades institucionais e educativas desse contexto, apontando para uma transformação nas práticas e no pensar o acesso e acessibilidade museal, que ultrapassa a visão de que pessoas com deficiência são o único público alvo desse tipo de ações. A autora demonstra como ações de acessibilidade contribuem para o desenvolvimento de público e para a democratização dos museus.

A professora e museóloga Mona Nascimento e Leane Cristina Ferreira Gonçalves, no artigo Educação museal em rede: surgimento e atuação das redes de educadores em museus no Brasil, nos falam da importância das redes, em especial as Redes de Educadores em Museus, para o desenvolvimento da educação museal no Brasil. Criadas como movimentos ativos e informais, inicialmente com objetivos voltados para a troca de experiências e a formação dos educadores museais, essas organizações têm-se transformado em verdadeiros sujeitos políticos, contribuindo para o desenvolvimento do campo da educação museal e para seu fortalecimento, mais recentemente atuando fortemente na construção participativa da Política Nacional de Educação Museal e na sua implementação. Partindo do levantamento histórico sobre a criação das REMs que tem como marco o ano de 2003, com a criação da Rede de Educadores em Museus e Centros Culturais do Rio de Janeiro, as autoras demonstram a relevância das redes no cenário da sociedade civil organizada, demonstrando como o próprio conceito de rede foi 


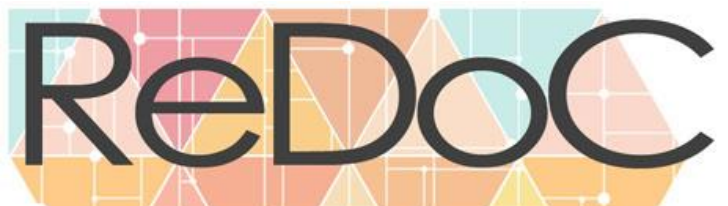

\section{Revista Docência e Cibercultura}

traduzido em realidade na criação de diversas redes de educadores em museus estaduais e da Rede de Educadores em Museus do Brasil.

O artigo Política Nacional de Educação Museal - PNEM: Museus, Educação em Redes de Márcia Isabel Teixeira de Vargas, professora e integrante da REM/RS e de Andréia von Hausen Bederode Becker apresenta uma análise do cenário emergido com a efetivação da Política de Educação Museal (PNEM) e a participação das Redes de Educadores em Museus, vivenciadas pelos sujeitos da dinâmica educacional em instituições culturais desde a sua concepção. O artigo também narra a participação da Rede de Educadores em Museus do Rio Grande do Sul (REM-RS), na elaboração compartilhada da Política Nacional de Educação Museal, no período de 2012 a 2017, e tem o objetivo de evidenciar tensões experimentadas pelo museu, a escola e por seus agentes nas atividades do setor educacional museológico. A partir dessas experiências, as autoras sugerem as ações empreendidas para fomentar a incorporação da PNEM às instituições museológicas sejam efetivadas de forma articulada e com indispensável reconfiguração de acordo com os princípios e diretrizes da política pública voltada aos museus brasileiros, enquanto referencial para o setor.

Em Novas práticas sociais no campo da educação museal: a cultura digital e a sociabilidade em rede, Luciana Conrado Martins, educadora museal e pesquisadora da Percebe Educa, apresenta uma reflexão acerca dos usos e impactos das tecnologias digitais na educação museal, no que tange à compreensão de seus efeitos e possibilidades para além do simples uso direto. A partir de uma discussão teórica, a autora debate como os educadores museais podem, frente às perspectivas apontadas pelos novos cenários informacionais, estabelecer processos de sociabilidade em rede por meio das novas práticas sociais vivenciadas pela cultura digital e como isso reflete as orientações da PNEM.

No último artigo deste volume, Mila Chiovatto, coordenadora do Núcleo de Ação Educativa da Pincoteca do Estado de São Paulo faz um relato sobre a experiência inédita de uso da tecnologia Watson de Inteligência Artificial em Watson, uso de Inteligência Artificial (AI) $e$ processos educativos em museus. Desenvolvida pela IBM e aplicada nesse museu. Questionando o futuro da mediação cultural em museus, Mila apresenta como foi pensada e desenvolvida a experiência na Pinacoteca, apresentando a relação estabelecida entre diferentes setores do museu na concepção de conteúdos e metodologias de aplicação dessa tecnologia.

Além dos artigos apresentados, a Redoc traz duas resenhas de trabalhos acadêmicos do campo da educação museal: Isabel Mendes apresenta a tese de doutorado da educadora que fundou o Museu da Vida da FIOCRUZ, Ilone Seibel (in memoriam), O papel do setor educativo nos museus: análise da literatura (1987 a 2006) e a experiência do museu da vida, defendida em 2009, e representando uma produção recente do campo a dissertação de mestrado de Maria Clara Boing, coordenadora do Programa CCBB Educativo do Rio de Janeiro, A Educação praticada no/com o MAR: o que nos dizem gestos e narrativas dos Educadores do Museu? é apresentada pela autora. 


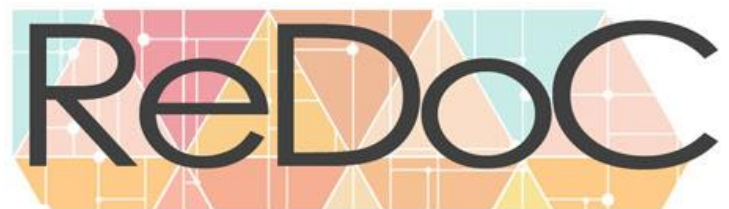

\section{Revista Docência e Cibercultura}

Três produções artísticas são também apresentadas no presente número: os vídeos da museóloga Aparecida Rangel, do Museu Casa de Rui Barbosa e do educador do Museu Histórico Nacional Diogo Tubbs, e a exposição fotográfica em $360^{\circ}$ de Shenia Mineiro. No primeiro, intituladoTod@s são tod@s?, Rangel apresenta uma ação educativa desenvolvida no Museu Casa de Rui Barbosa que abordou o público interno e que teve como produto o documentário de mesmo nome. Diogo Tubbs apresenta no vídeo "Museu de Afetos: uma parceria Museu Histórico Nacional e Museu Nacional" uma ação desenvolvida no Museu Histórico Nacional em homenagem ao Museu Nacional, incendiado no dia 2 de setembro de 2018. No minidocumentário, de cerca de cinco minutos, são feitas entrevistas afetivas e exibidas partes do desenvolvimento de uma visita e oficina de montagem de exposição, que teve como resultado a exibição de lembranças e peças de afeto que remetiam ao Museu Nacional.

Encerrando o Dossiê, a belíssima exposição online de Shenia Mineiro, formada em Letras, pósgraduada em língua portuguesa, graduanda do curso de Pedagogia da UERJ e que trabalha com audiovisual desde 2012, materializa em imagens as suas experiências como visitante de museus da cidade do Rio de Janeiro e de Friburgo, sua cidade de origem. Shenia narra brevemente as suas visitas aos seguintes museus fotografados: Museu Imperial de Petrópolis, Palácio do Catete, Museu do Índio, Museu Villa Lobos, Museu Casa de Rui Barbosa, Real Gabinete e o Planetário de Nova Friburgo. No final da exposição, a autora disponibiliza um link para os equipamentos culturais registrados em fotos em 360 graus.

Agradecemos todos os autores que contribuíram com a realização dessa tessitura praticoteórica, que foi elaborar e materializar o Dossiê Temático sobre Educação Museal da Revista Docência e Cibercultura. $\mathrm{O}$ agradecimento estende-se também às parcerias que realizamos na vida e na prática educativa. Agradecemos a Felipe Carvalho e Edmea Santos a acolhida e colaboração.

Esperamos que a leitura desse volume da Redoc seja prazerosa e contribua para a introdução e aprofundamento de estudos e pesquisas que tenham a educação museal como tema e inspiração. Os conteúdos aqui abordados relacionam-se com a prática educativa museal, mas também com sua relação com o universo escolar e de formação de professores. A elaboração desse Dossiê insere-se no debate e no desenvolvimento da educação museal como campo científico, profissional e de formação e está diretamente ligada à concretização da Política Nacional de Educação Museal. Aos novos viajantes desejamos que sejam bem-vindos a esse universo! E aos nossos pares, que aproveitem a leitura para se inspirarem a alçar novos vôos! Que todos espalhem essa publicação, para que vire semente! 


\section{REFERÊNCIAS}

AIDAR, Gabriela. ACESSIBILIDADE EM MUSEUS: IDEIAS E PRÁTICAS EM CONSTRUÇÃO. Revista Docência e Cibercultura, v. 3, n. 2, mai-ago, 2019, p. 155-175. DOI: https://doi.org/10.12957/redoc.2019.39810

BOING, Maria Clara. A EDUCAÇÃO PRATICADA NO/COM O MAR: O QUE NOS DIZEM GESTOS E NARRATIVAS DOS EDUCADORES DO MUSEU? Revista Docência e Cibercultura, v. 3, n. 2, mai-ago, 2019, p. 334-343. DOI: https://doi.org/10.12957/redoc.2019.44523

CASTRO, Fernanda Santana Rabello de. A CONSTRUÇÃO DO CAMPO DA EDUCAÇÃO MUSEAL: POLÍTICAS PÚBLICAS E PRÁTICA PROFISSIONAL. Revista Docência e Cibercultura, v. 3, n. 2, mai-ago, 2019, p. 90-114. DOI: https://doi.org/10.12957/redoc.2019.40706

CHIOVATTO, Mila. WATSON, USO DE INTELIGÊNCIA ARTIFICIAL (AI) E PROCESSOS EDUCATIVOS EM MUSEUS. Revista Docência e Cibercultura, v. 3, n. 2, mai-ago, 2019, p. 217-230. DOI: https://doi.org/10.12957/redoc.2019.40293

COSTA, Andrea. A FORMAÇÃO INICIAL E CONTINUADA DE EDUCADORES MUSEAIS: PROJETO EM CONSTRUÇÃO. Revista Docência e Cibercultura, v. 3, n. 2, mai-ago, 2019, p. 67-89. DOI: https://doi.org/10.12957/redoc.2019.44693

GRUZMAN, Carla; SOARES, Ozias. O LUGAR DA PESQUISA NA EDUCAÇÃO MUSEAL: DESAFIOS, PANORAMAS E PERSPECTIVAS. Revista Docência e Cibercultura, v. 3, n. 2, mai-ago, 2019, p. 115-139. DOI: https://doi.org/10.12957/redoc.2019.39809

MARTI, Frieda; e SANTOS, Edméa. EDUCAÇÃO MUSEAL ONLINE: A EDUCAÇÃO MUSEAL NA/COM A CIBERCULTURA. Revista Docência e Cibercultura, v. 3, n. 2, mai-ago, 2019, p. 41-66. DOI: https://doi.org/10.12957/redoc.2019.44589

MARTINS, Luciana Conrado. NOVAS PRÁTICAS SOCIAIS NO CAMPO DA EDUCAÇÃO MUSEAL: A CULTURAL E A SOCIABILIDADE EM REDE. Revista Docência e Cibercultura, v. 3, n. 2, mai-ago, 2019, p. 199-216. DOI: https://doi.org/10.12957/redoc.2019.44795

MENDES, Isabel. CONTRIBUIÇÕES DE ILONI SEIBEL (1941-2013) PARA OS SETORES EDUCATIVOS DE MUSEUS. Resenha da tese de doutorado "O papel do setor educativo nos museus: análise da literatura (1987 a 2006) e a experiência do museu da vida". Revista Docência e Cibercultura, v. 3, n. 2, mai-ago, 2019, p. 328-333. DOI: https://doi.org/10.12957/redoc.2019.44518

MINEIRO, Shenia. MEMÓRIAS DE FORMAÇÃO. Revista Docência e Cibercultura, v. 3, n. 2, mai-ago, 2019, p. 356-362. DOI: https://doi.org/10.12957/redoc.2019.44317 


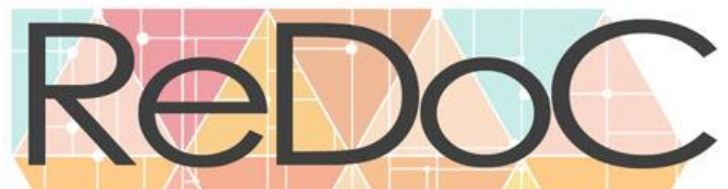

\section{Revista Docência e Cibercultura}

NASCIMENTO, Mona; e GONÇALVES, Leane Cristina Ferreira. EDUCAÇÃO MUSEAL EM REDE: SURGIMENTO E ATUAÇÃO DAS REDES DE EDUCADORES EM MUSEUS NO BRASIL. Revista Docência e Cibercultura, v. 3, n. 2, mai-ago, 2019, p. 140-154. DOI: https://doi.org/10.12957/redoc.2019.39944

RANGEL, Aparecida.TOD@S SÃO TOD@S? Revista Docência e Cibercultura, v. 3, n. 2, mai-ago, 2019, p. 350-355. DOI: https://doi.org/10.12957/redoc.2019.44956

TUBBS, Diogo. MUSEU DE AFETOS: UMA PARCERIA MUSEU HISTÓRICO NACIONAL P MUSEU NACIONAL. Revista Docência e Cibercultura, v. 3, n. 2, mai-ago, 2019, p. 347-349. DOI: https://doi.org/10.12957/redoc.2019.44915

VALENTE, Maria Esther; CAZELLI, Sibelle. INCURSÕES SOBRE OS TERMOS E CONCEITOS DA EDUCAÇÃO MUSEAL. Revista Docência e Cibercultura, v. 3, n. 2, mai-ago, 2019, p. 18-40. DOI: https://doi.org/10.12957/redoc.2019.40729

VARGAS, Márcia Isabel Teixeira de; e BECKER, Andréia von Hausen Bederode. POLÍTICA NACIONAL DE EDUCAÇÃO MUSEAL - PNEM: MUSEUS, EDUCAÇÃO E REDES. Revista Docência e Cibercultura, v. 3, n. 2, mai-ago, 2019, p. 176-198. DOI: https://doi.org/10.12957/redoc.2019.44362 